\title{
GEOLOCATION-ENABLED MOBILE WEB PROJECTS FOR SMARTPHONES IN THE CIS CURRICULUM
}

\author{
Danial L. Clapper, Western Carolina University, clapper@email.wcu.edu \\ Barbara Jo White, Western Carolina University, whiteb@email.wcu.edu \\ William Richmond, Western Carolina University, brichmond@email.wcu.edu
}

\begin{abstract}
Mobile devices and accessing mobile applications have become critical components of our daily individual and corporate lives. This paper discusses one Information Systems (IS) program and its experiences incorporating mobile web application projects into its existing curriculum. The benefits, for both faculty and students, of working on mobile web projects, often "campus tour" types of projects for university division clients, are also discussed.
\end{abstract}

Keywords: Mobile Web, Projects, Smartphone Applications, Teams

\section{INTRODUCTION}

The mobile smartphone market accounted for 22\% of the global market for sales of handsets in 2010. The global market for smartphones is forecast to nearly triple, from US \$55.4 billion in 2009 to US \$150.3 billion in 2014 [5]. This increase in consumer demand may translate to more jobs for IS students. Not only might jobs be created for students who know how to integrate mobile technology with existing systems, but the increase in consumer demand will likely fuel the increase in demands for mobile applications [1].

Preparing our students for the technology trend toward increased mobile devices and applications requires changes to our current curriculum. Institutions of higher education can lead the way by incorporating mobile applications into their current IS programs.

\section{Adding Mobile Development to the Curriculum}

One approach to adding mobile development to the curriculum is to create specific courses. Often, these courses are electives and attract students with an interest in the mobile development area. A specific mobile development elective course can be taught as a traditional course or it can be offered to individual students as independent study courses.

Another way to introduce mobile development to a larger set of students is through the use of projects in capstone courses such as Systems Analysis and Design or Systems Implementation capstone courses.

This study examines the incorporation of mobile application development into an information systems capstone course at a regional comprehensive university located in a rural southeastern area of the United States.

\section{STRUCTURING IS CAPSTONE PROJECTS}

Structuring capstone projects involving mobile technologies is similar to other capstone projects in that teams of students work on information systems projects over the course of a semester. However, mobile development projects, particularly geolocation-enabled projects, differ from other capstone projects in that new development tools are needed to facilitate work on these geolocation-enabled projects using smartphone capabilities without travelling to site-specific locations for testing. Issues such as client identification, mobile development approaches, student team structure, and development tools are discussed below.

\section{Identifying Clients}

Incorporating projects into IS courses can involve working on everything from simulated projects to real projects with real clients. Working on simulated projects allows students the opportunity to focus solely on the development 
effort since there is no client interaction. However, projects using real clients (employees, owners or stakeholders in currently-operating businesses) offer students the opportunity to work in a more real-world environment interacting and communicating with clients with varying technical backgrounds.

Real clients originate from various community entities. The university setting provides a wealth of opportunities for working with real clients, many of whom are interested in tour-based projects such as art and entertainment tours, campus tours for potential students or discipline-based interests, such as history-based tours. In addition, similar opportunities exist for working with local and county governments providing tours for citizens. In those cases, students can often gather requirements for county government based projects while home during the summer or academic-year breaks.

Working with real clients provides several benefits. For the department, the mobile projects have generated ongoing publicity and interest. Our end-of-year capstone presentations are now held in our auditorium and attract audiences from several distinct areas: IS students with several semesters left before the capstone; IT employees interested in mobile development; and campus employees who work directly with the students on mobile development projects as clients or campus employees who would like IS students to develop a project for their functional area or department. The projects have now attracted the interest of the university public relations department which has written an article on one of our student-developed mobile projects-a collaborative effort involving the student affairs department which in turn has helped build political support and goodwill for the IS department in the College of Business.

In addition to publicity and interest on campus, work with real clients has also produced internship opportunities for our students. For example, one student first began working on a mobile web tour for Catawba County localgovernment during the systems analysis and design class in the fall, worked on implementing this app during the spring semester and then secured an internship for the summer to continue adding features to the app.

Plans are also in place for the student to present his work with Catawba County at the North Carolina Local Government Information Systems Association (NCLGISA) Fall 2011 symposium. NCLGISA is a very active, large organization of IS professionals working with local governments in NC. The organization provides members with a variety of benefits, some of which are the two technology symposiums per year where IS professionals and vendors meet to share experiences and ideas.

Students presenting on mobile web development projects have the opportunity to meet hundreds of IT professionals and vendors in the exhibit area, with whom they can discuss internship and job possibilities. IS projects that go beyond the classroom in which students work on real projects with an external business partner, such as a county government, as well as a professional organization, such as NCLGISA, provide students with multiple networking opportunities [3].

\section{Choosing a Mobile Development Approach}

A fundamental choice instructors need to make is the approach for mobile development. When most people think of smartphone applications, they are thinking of native apps. A native app is a program designed to run on a specific smartphone platform, such as iPhone or Android. Native apps are downloaded from online stores such as Apple's App Store or the Android Market. The languages and tools used to create a native app for one platform are quite different than those used to create an app for a different phone platform. For example, Xcode, Cocoa and Objective C are usually used to create an iPhone app, while Eclipse and Java are commonly used to create Android applications. The learning curve for both of these platforms is steep (particularly for students) and unique to the platform with little overlap between the platforms. That is, the training required for one platform is quite different than the training required for a different platform.

Although considerably less well-known, another approach to mobile development is browser-based mobile web development. In this approach, the goal is to create an application that runs in the browser of the smartphone. One advantage to this approach is that an application that runs in the browser of an iPhone should (with the proper design) also run in the browser of an Android device. Therefore a different app is not required for the different smartphone platforms. Another advantage to this approach is that it typically uses web standards such as HTML, 
Volume XII, No. 2, pp. 53-62, 2011

Cascading Style Sheets (CSS) and Javascript. Because this approach uses standard technologies, student learning is applicable to both mobile development and traditional web development. The learning curve for these standard technologies is substantially lower than for technologies used for creating native apps. A disadvantage to this approach is that the program is typically much more limited in its ability to access phone features such as contacts, file system, and the camera, among others.

In our curriculum, we did not have the electives needed for the students to learn native app development, so instead we did a mini-self study course with study material and exercises which the students could work through prior to beginning their capstone course. The self study covered topics such as javascript, css, and geolocation, which were not previously covered in the curriculum. This self-study was also available as a one-hour course if the students preferred, but most elected to complete the material outside without receiving official course credit. While not all of the students who start the self-study complete it, most do and then have a good foundation for developing geolocation-enabled mobile web apps in their capstone course.

\section{STRUCTURING STUDENT TEAMS}

Given the decision to create mobile web applications, students typically worked in teams of three with precisely defined roles. Those roles were: Client side Developer, Server side Developer and Client Liaison.

This section covers basic role responsibilities and uses examples from the various tour-based projects from the CIS implementation capstone course. Images are drawn from student work with Cherokee History Campus Tour, Student-Driven Campus Tours, Campus Sculpture Tours and Catawba County Mobile Tours.

\section{Client-side Development Role for Mobile Web Tour Projects}

Client side developers used Javascript and CSS along with geolocation and Google Maps to create the mobile web apps that ran in the browser of the user's smartphone. The opening page of each mobile web tour gives the user the options of viewing locations, each referred to as a Point of Interest (POI), on a map or in a list.

Figure 1: Start screen for mobile web tour app

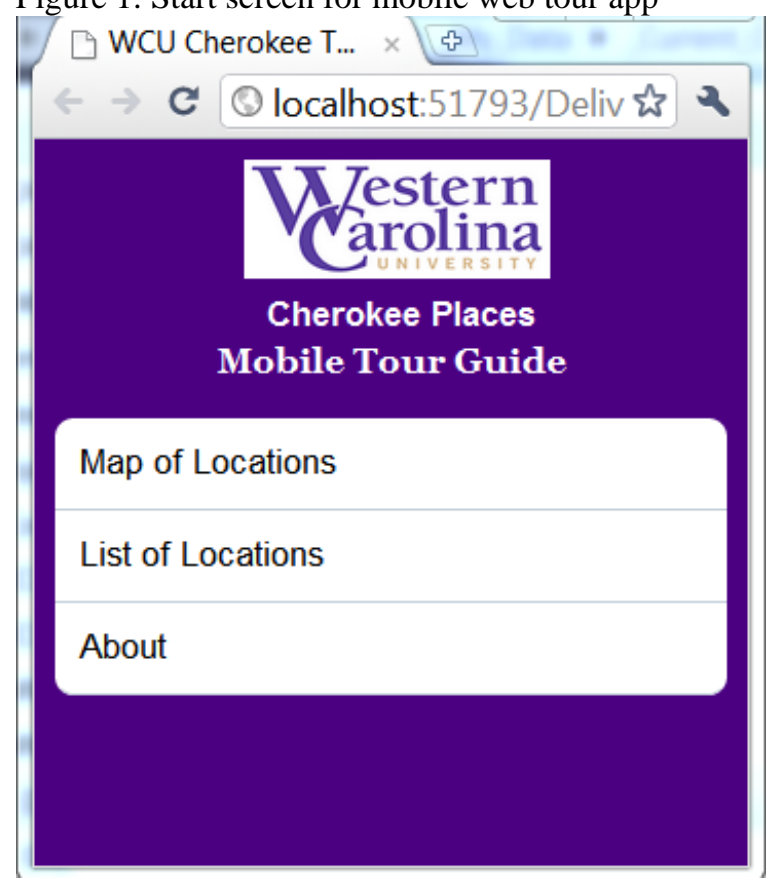




\section{Volume XII, No. 2, pp. 53-62, 2011}

If users would like to see a list of the POIs, they would choose that option and then see a list as shown in Figure 2. Whether in list view or map view, users have the option to drill down on specific POIs for more information.

Figure 2: List view of points of interest on tour

\begin{tabular}{|l|l|}
\hline List - WCU Chero... \\
Places by Distance \\
\hline Stickball Field: 0.48 miles \\
\hline Town Plaza: 0.52 miles \\
\hline Council House: 0.53 miles \\
\hline Cherokee Town (Chota): 0.53 miles \\
\hline Indian Mound: 0.56 miles \\
\hline Fresh Water: 0.58 miles \\
\hline Cherokee House: 0.6 miles \\
\hline Buzzards Roost: 0.7 miles \\
\hline Cullowhee Creek: 2.8 miles \\
\hline
\end{tabular}

Using the geolocation capability of the user's smartphone, the app determines the user's current location. In addition, the app also displays the distance to each of the POIs. Then, the POIs are shown in a list form sorted by distance (from nearest to farthest).

As the user walks from one location to another, the application recalculates distances and resorts the list automatically showing the new nearby POIs relative to the user's location.

If, from the start screen, users choose the Map view of the tour, Figure 3 shows the screen they would encounter. 
Volume XII, No. 2, pp. 53-62, 2011

Figure 3: Map view of points of interest on tour

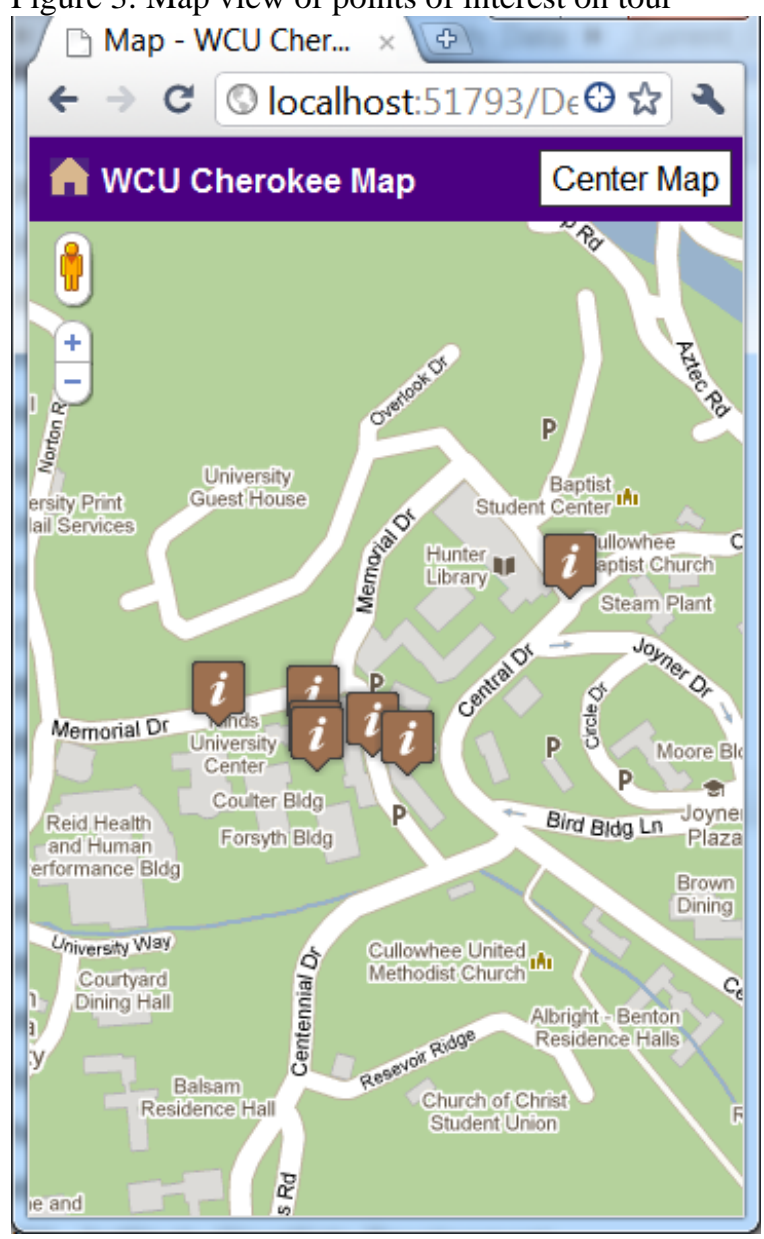

From either the List view or the Map view, the user can choose a specific POI and view information about it as shown in Figure 4.

This page initially shows the users some information about the POI and allows them to view additional information if they desire. It also contains pictures of the POI.

Recently, while investigating requirements for a campus art museum outdoor sculpture tour, the director of the museum expressed interest in having audio files associated with the POI. This would allow artists to communicate directly with sculpture viewers. Although the iPhone and Android browsers handle playing audio a little differently, it is not difficult to program around these differences. 
Volume XII, No. 2, pp. 53-62, 2011

Figure 4: Information about a point of interest

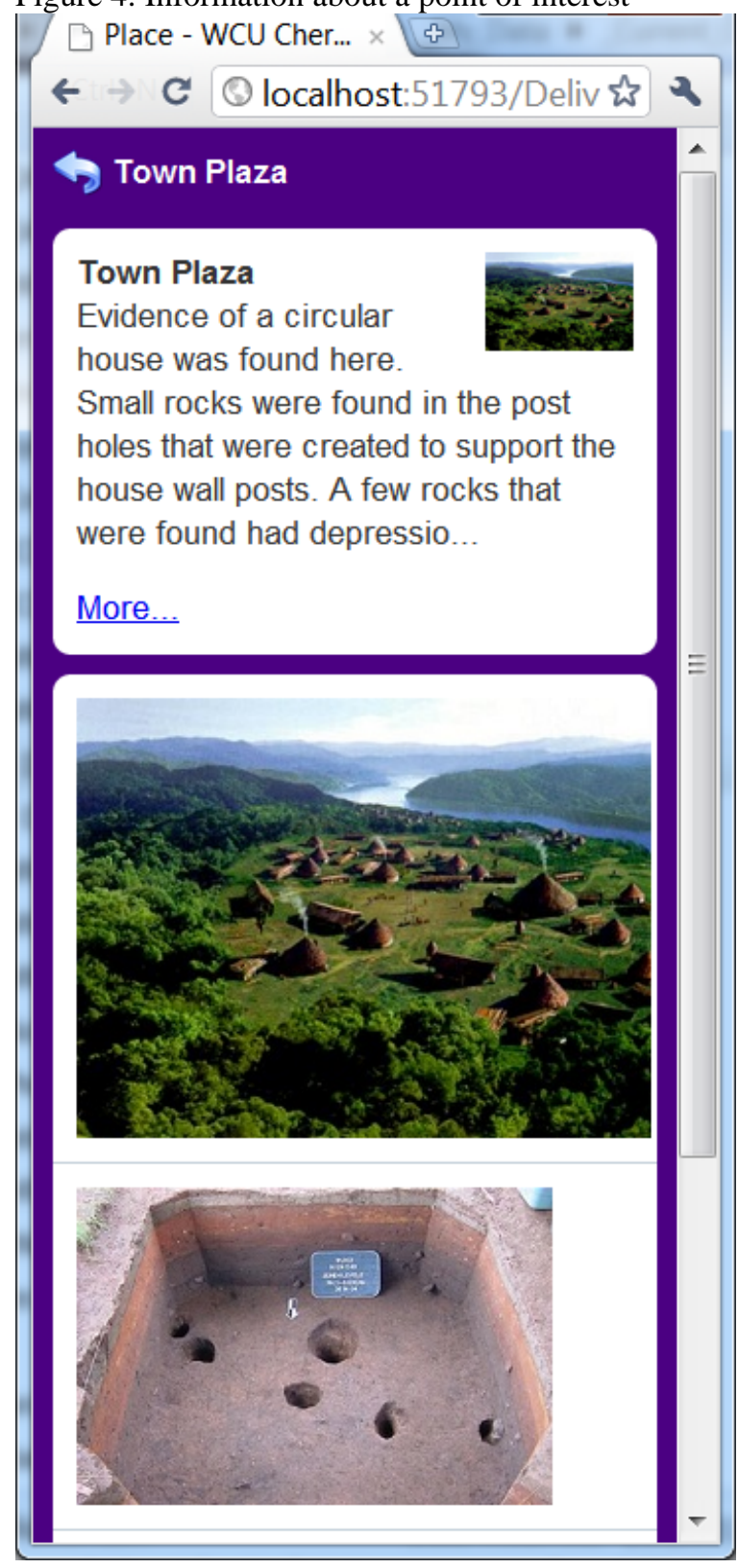

\section{Server-side Development Role for Mobile Web Tour Projects}

While the client-side developer worked on building the mobile web tour Server-side developers worked on the Administration and content creation tools that ran on a web server using C\# and ASP.net. Specifically, the serverside developer worked on developing the administrative tools that would allow an administrator to add a POI to the tour and update or delete an existing POI. These tools were created using C\# and ASP.net and reside on the same server as the mobile web application. Because these tools should be accessed only by the administrator of the tour, they require password authentication before they can be used. Unlike the mobile web tour pages, these tools are designed to be used by the administrator on a desktop computer -- although these pages also run in a browser. Figure 5 shows the interface for the tool that allows the administrator to add a new POI to the tour. 
Volume XII, No. 2, pp. 53-62, 2011

Figure 5: Administrative page to add new POI

\section{Cherokee Places - Admin Tools}

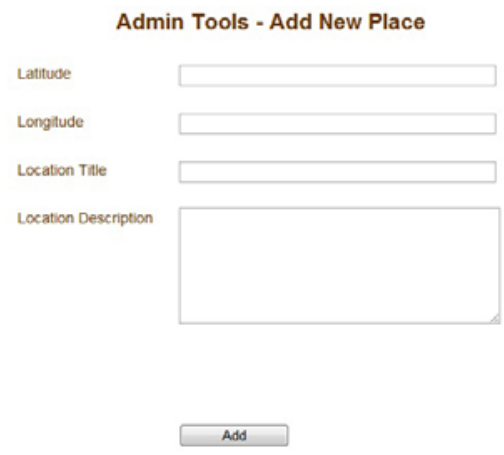

$\approx$ Admin Start

Once the POI has been added to the tour the client can also upload images for it and update both the images and information for any POI on the tour.

Figure 6 shows the initial page that allows administrators to choose the POI which they would like to update.

Figure 6: Choosing a POI to update

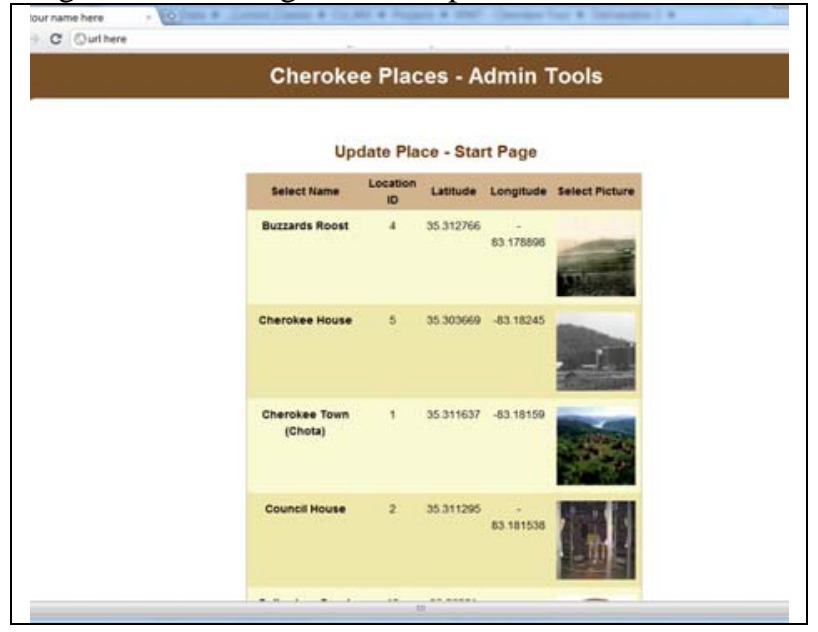

The administrator clicks on one of the POIs to select the POI to update, as shown in Figure 7. Once updates are authorized, they can become part of the tour. 
Volume XII, No. 2, pp. 53-62, 2011

Figure 7: Updating a POI

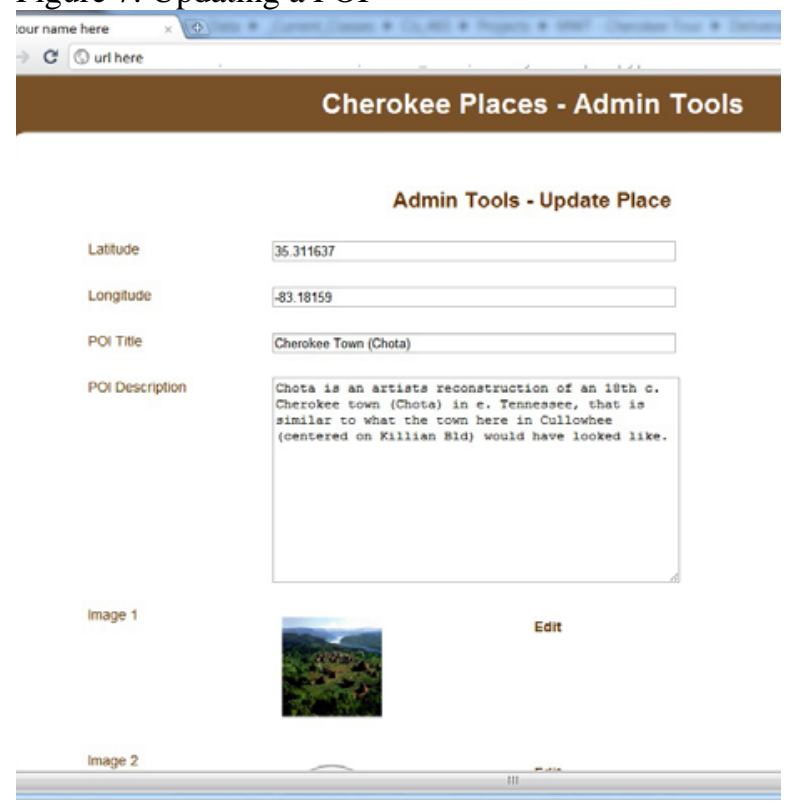

\section{Client Liaison Role for Mobile Web Tour Projects}

The Client Liaisons are responsible for working with clients, usability testing and acceptance testing and deployment of the deliverables. While this is the least technical role, it is critical for a successful project.

The client liaisons must establish regular communications with their clients. They must manage their client's expectations to ensure that the project scope does not expand beyond the time and skills of the other team members. They are responsible for obtaining the tour content and ensuring that it is appropriate for a mobile device.

As the project progresses, they must show the client the tour, get feedback and then present that information to the team to determine which requested changes are reasonable. Finally, they must document the system, especially the administrative system in a manner that will allow the client to update the tour content. Because the student team will disperse at the end of the semester, the only support the client will have on the system is the documentation prepared by the liaison.

\section{Tools to Facilitate Mobile Web Application Development in the IS Curriculum}

One of the challenges of developing mobile apps is testing. While a desktop environment is where the applications are created, the environment in which the applications run is a mobile one and ultimately smartphones with data plans are needed to insure that the apps run as planned.

Unfortunately, both the phones and their plans will probably not be an easy addition to a department's course-related expenses.

There are a number of solutions that can help with this problem. Probably the most valuable of these are emulators.

The Android emulator is available as part of the free Android SDK [2] and is a reasonable substitute to a phone for seeing the look and feel of the application in the small screen of a smart phone. Figure 8 shows the Android emulator interface. The Android emulator also allows the tester to feed GPS coordinates into it (either singly or as a 
Volume XII, No. 2, pp. 53-62, 2011

path) to check the GeoLocation features of the app. As of Fall 2011, the free iPhone simulator, which is available to licensed Apple developers as part of the iOS SDK [4] does not allow the input of test GPS coordinates.

Figure 8: Android Emulator Interface

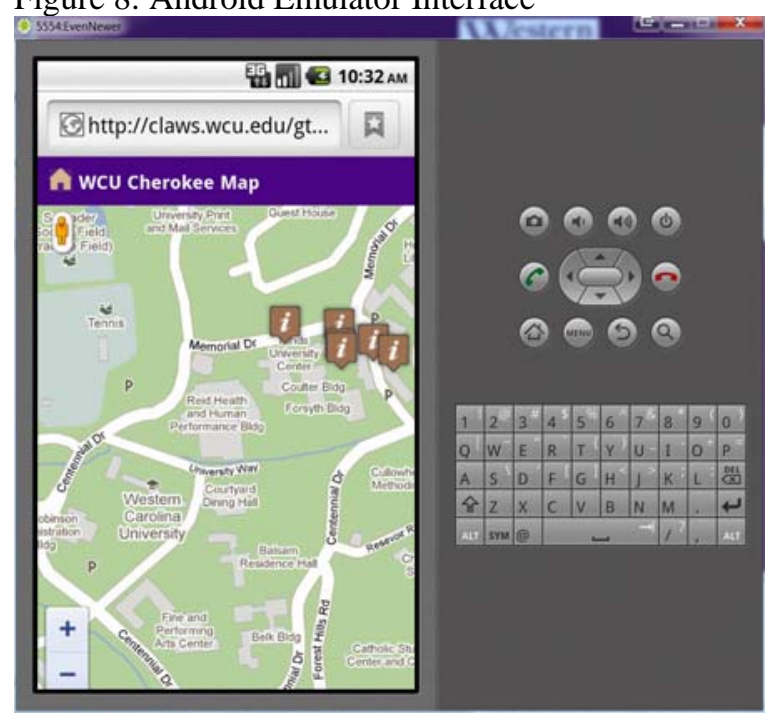

If accuracy of the coordinates are not crucial, the desktop versions of both Chrome and Safari (the two desktop browsers that are most similar to the the Android and iPhone browsers) will retrieve GPS data for the web apps.

Since neither desktops nor laptops typically have a GPS chip, the browsers generate estimated GPS coordinates. These can easily be a mile off, but at least allow testing the general geolocation functionality of the apps.

A low-cost option to testing on an iPhone is an iPod Touch. Although this doesn't have a GPS chip, it will use WiFi to get an approximate GPS location. Sometimes this can be quite accurate and others it can be very inaccurate. Also in order for this to work you must be in range of a WiFi signal. This often is not a problem on a college campus but certainly could be a problem in many other settings.

\section{SUMMARY}

We have described how one university integrated location-based mobile browser-based projects into its IS capstone course. These projects are ideal for an IS capstone. They prepare students for growing market, while building on traditional software develop skills and courses. Students considered it "cool" technology, so they are excited by the projects.

These projects provide all of the benefits associated with working with real projects. The students must interact with real clients, learning to manage their expectations and communication as well as developing the software. A successful project results in material for a resume and potentially references from their client.

These mobile application projects also benefit the faculty leading the course. There are lots of potential clients, so it is easy to find projects. Many potential clients are campus partners which makes managing the project easier both for the faculty member and the students. As with students, successful projects provide a showcase for the IS department and its support of other university divisions and of the local community. 
Volume XII, No. 2, pp. 53-62, 2011

\section{REFERENCES}

1. Computer Software Engineers and Computer Programmers. (n.d.). Available: http://www.bls.gov/oco/ocos303.htm

2. Download the Android SDK. (n.d.). Available: http://d.android.com/sdk/index.html

3. Grant, D. M., Malloy, A. D., Murphy, M. C., Foreman, J., \& Robinson, R. A. (2010). Real World Project: Integrating the classroom, external business partnerships and professional organizations. Journal of Information Technology Education: Innovations In Practice, 9, IIP 167-196.

4. $\quad$ iOS Dev Center. (n.d.). Available: http://developer.apple.com/devcenter/ios/index.action

5. Global Mobile Phone \& Smartphone Market (2010-2015). (2011). Available:

http://www.marketsandmarkets.com/Market-Reports/smartphone-market-219.html 